\title{
Retraction Note to: Dynamic identification of coastal climate characteristics and traditional residential space design based on multi-source remote sensing images
}

\author{
Shangcao $\mathrm{Li}^{1}$ - Jae Chul Park ${ }^{1}$ Tianlong Chai ${ }^{1}$ Xuesong Gao ${ }^{1}$
}

Published online: 13 December 2021

(c) Saudi Society for Geosciences 2021

Retraction Note to: Arabian Journal of Geosciences (2021) 14: 923 https://doi.org/10.1007/s12517-021-07216-x

The Editor-in-Chief and the Publisher have retracted this article because the content of this article is nonsensical. The peer review process was not carried out in accordance with the Publisher's peer review policy. The authors have not responded to correspondence regarding this retraction.

The original article can be found online at https://doi.org/10.1007/ s12517-021-07216-x.

Tianlong Chai

zw_9187@126.com

1 College of Science and Technology, Woosuk University,

Samrae, Jeonju, South Korea 